\title{
PHAGOCYTOSIS BY HUMAN LEUCOCYTES. I. EFFECT OF FIBRIN ON PHAGOCYTOSIS OF STAPHYLOCOCCI AND OF ENCAPSULATED PNEUMOCOCCI BY NORMAL HUMAN LEUCOCYTES ${ }^{1}$
}

\author{
BY HENRY H. BALCH 2 AND MARGARET T. SPENCER \\ (From the Department of Surgery, New York University College of Medicine and the Third \\ (New York University) Surgical Division, Bellewue Hospital, New York, N. Y.)
}

(Submitted for publication February 4, 1953; accepted June 23, 1954)

Resistance to phagocytosis by pathogenic microorganisms may be due to a variety of mechanisms depending on the species. For example, bacteria may produce substances toxic for leucocytes such as the "leucocidins" produced by staphylococci and hemolytic streptococci. Another mechanism suggested by Hale and Smith (1) may operate in the case of pathogenic staphylococci; these bacteria produce an enzyme, coagulase, which acting in concert with a serum factor catalyzes the conversion of fibrinogen to fibrin. According to Hale and Smith, the fibrin meshwork so formed, impedes the activity of the leucocytes, and furthermore, fibrin, intimately deposited about the staphylococci, in some way interferes with their ingestion.

Rogers and Tompsett (2), using human leucocytes, confirmed the observation that coagulaseproducing staphylococci are less well ingested than coagulase negative strains, but believe that the observed difference was not of sufficient magnitude to be a factor of major importance in explaining the difference in pathogenicity between the two species.

The production of capsules by certain bacterial species can be correlated with pathogenicity. Specific anticapsular serum renders the encapsulated organism relatively defenseless to leucocyte activity. Wood, Smith, and Watson $(3,4)$ have shown, however, that encapsulated pathogens may be ingested in the absence of specific antibody both in vitro and in vivo provided the leucocytes can push the organisms against a nonyielding surface. A fibrin meshwork such as occurs in blood clots or inflammatory exudates offers an excellent matrix

1 This study was supported in part by a contract with the Medical Research and Development Board of the Office of the Surgeon General, U. S. Army.

2 Markle Scholar in Medical Science. Present address : Division of Surgery, Army Medical Service Graduate School, Walter Reed Army Medical Center, Washington 12 , D. C. for phagocytosis in the absence of antibody (5). The validity of "surface phagocytosis" is unquestioned, but its quantitative significance in vivo has not been defined.

The observed difference in the effect of fibrin on the ingestion of coagulase positive staphylococci and encapsulated pneumococci suggests that enzymatic therapy designed to reduce the amount of fibrin in inflammatory lesions $(6,7)$ may increase or diminish natural phagocytosis depending on the microorganisms involved.

An attempt has been made in the present study to confirm the observations of Hale and Smith (1) on the influence of coagulase production by staphylococci on phagocytosis and to determine the effect of streptokinase on this process. In addition, surface phagocytosis of type II encapsulated pneumococci has been studied quantitatively and the effect of streptokinase on it has been evaluated.

\section{METHODS}

The influence of coagulase on the ingestion of staphylococci by human leucocytes was determined by (a) comparing the ingestion of coagulase positive with the ingestion of coagulase negative staphylococci under identical conditions, and (b) by comparing the ingestion of coagulase positive strains in coagulable and noncoagulable media.

\section{Roller tube technique}

One-tenth milliliter of a standardized suspension of organisms was added to $1.0 \mathrm{ml}$. human blood (either heparinized, streptokinase-treated, defibrinated, or defibrinated plus streptokinase). The mixtures were placed in glass tubes $12 \times 0.8 \mathrm{~cm}$. in size, sealed and rotated at 8 R.P.M. in an incubator at $37^{\circ}$ C. for one hour. Smears were made and phagocytosis recorded as the average number of organisms ingested per polymorphonuclear leucocyte; neutrophils were counted regardless of whether ingestion had occurred. Four coagulase positive staphylococcal strains (I, II, III, and IV) and one coagulase negative strain were used. Staphylococci were grown in 
fresh beef heart infusion broth containing 1 per cent neopeptone; overnight cultures were used which were centrifuged, and suspensions standardized turbidimetrically so as to contain approximately $1.5 \times 10^{\circ}$ organisms per ml. Suspensions were tested for coagulase production in each experiment, using the tube test.

Blood samples were handled as follows: $18 \mathrm{ml}$. was drawn into a dry syringe and rendered noncoagulable by the addition of approximately $2 \mathrm{mg}$. heparin. A second specimen was drawn into a dry syringe and rendered noncoagulable by two methods: (a) the addition of streptokinase which promotes the breakdown of fibrin and fibrinogen (blood plus streptokinase), and (b) by defibrination with the use of glass beads (defibrinated blood). In the former method, the quantity of streptokinase (Varidase, Lederle) used was arbitrarily chosen as the least amount which would cause lysis in less than 2 minutes at $37^{\circ} \mathrm{C}$. when incorporated in a plasma clot. The amount used to defibrinate blood was approximately 800 units per ml. of blood, and varied to some extent with different batches of enzyme. The designation, blood plus streptokinase, used in this paper refers to blood which had clotted but in which fibrinolysis had occurred subsequently due to enzyme activity. In the second method of defibrinating blood, many leucocytes are caught in the fibrin strands about the beads; therefore, it is necessary to add viable leucocytes to the defibrinated blood. This was accomplished by adding the washed red and white cells from a known volume of heparinized blood to the serum from an equal volume of defibrinated blood from the same donor. Cells were washed twice in Tyrode's solution and were centrifuged at $4^{\circ}$. C. A control specimen of blood used in these experiments was labelled defibrinated blood plus streptokinase and consisted of defibrinated blood to which approximately 800 units of streptokinase had been added. The dilution of blood by streptokinase was controlled by the addition of an equal volume of 0.9 per cent saline to the other preparations (14 per cent of total volume of blood). The number of leucocytes per cubic millimeter was determined for each preparation of blood. Blood used was obtained from 17 healthy human donors.

\section{Technique for surface phagocytosis}

Surface phagocytosis was studied quantitatively in the following manner: $1.5 \mathrm{ml}$. of blood (either heparinized, streptokinase-treated, or defibrinated) was mixed with $0.2 \mathrm{ml}$. of a standardized suspension of organisms $(1.5 \times$ $10^{\circ}$ per ml.) in a 15-centimeter Petri dish to which 0.1 ml. of thrombin was added. A clot formed in only the heparinized blood. The mixture was then incubated at $37^{\circ} \mathrm{C}$. for one hour at which time $0.5 \mathrm{ml}$. of streptokinase (1,250 units) was layered on the preparation. After further incubation for one hour, smears were made from the liquefied mixture. Phagocytosis was recorded as the average number of organisms ingested per neutrophilic polymorphonuclear leucocyte. In this way a comparison was obtained of the ingestion of four different bacterial strains under the same conditions: coagulase positive staphylococcus, coagulase negative staphylococcus, encapsulated type II pneumococcus (strain D39S), where virulence was maintained by mouse passage, and a rough mutant of the latter (strain 36A). Ingestion of type II pneumococcus was also measured in the presence of type II antipneumococcal rabbit serum. Control mixtures contained normal rabbit serum in place of antipneumococcal serum. Four-hour 0.1 per cent glucose beef heart infusion broth cultures of pneumococci were used, centrifuged and standardized turbidimetrically to contain approximately $1.5 \times 10^{\circ}$ organisms per $\mathrm{ml}$. Staphylococci were prepared as described under the roller tube technique. Phagocytosis of each bacterial strain was determined in three different blood preparations: heparinized blood, blood defibrinated by streptokinase ( 800 units per ml.), and blood defibrinated by shaking with glass beads as described above. The number of leucocytes per cubic millimeter was counted in each blood preparation so that the ratio of organisms to leucocytes in each mixture was known. Blood from a series of 20 healthy human donors was used in tests carried out in Petri dishes.

\section{RESULTS}

\section{Roller tube technique}

Table I records mean ingestion of $(\mathrm{C}+)$ and (C-) staphylococci by neutrophils in four different blood preparations: blood plus heparin, blood plus streptokinase, defibrinated blood, and defibrinated blood plus streptokinase. Mean ingestion of all coagulase positive strains (I, II, III, and IV) has been recorded in each preparation because this was not significantly different with individual strains.

In comparing neutrophil ingestion, it may be important to keep the ratio of bacteria to phagocytes constant $(8,9)$. In the present experiments the bacterial suspensions used were always adjusted to the same turbidity and the neutrophil count per cubic millimeter determined for each blood preparation. The over-all ratio averaged 1 neutrophil to 50 bacteria. Since bacteria were always present in considerable excess, the differences in ratio of bacteria to neutrophils in different experiments is probably not an important factor. In any event, under the conditions of our experiments, the degree of phagocytosis appeared to be independent of the neutrophil count. A similar observation was recorded by another group of investigators (10).

Ingestion of ( $C-$ ) staphylococci. There was no significant difference in the ingestion of $(\mathrm{C}-$ ) staphylococci by neutrophils in heparinized blood, streptokinase-treated blood, blood defibrinated 
with glass beads, or in the latter containing streptokinase. Therefore, it may be concluded that in these experiments, heparin and streptokinase did not affect phagocytosis; this agrees with the findings of others (11-13). The data also show that the removal of fibrinogen with glass beads does not influence ingestion.

Ingestion of $(C+)$ staphylococci. There was a significant reduction in the mean ingestion of $(C+)$ staphylococci by neutrophils in heparinized blood compared with their mean ingestion by neutrophils in all the other blood preparations. However, significantly fewer $(\mathrm{C}+)$ staphylococci were ingested by leucocytes in streptokinase-treated blood compared with leucocytes in blood defibrinated by glass beads. The addition of streptokinase to the latter did not significantly alter the phagocytic index.

These data showed that coagulase-producing staphylococci were less readily ingested in the presence of fibrin, which agrees with the findings of Hale and Smith (1) and Rogers and Tompsett (2). But under the conditions of the present experiments considerably more $(\mathrm{C}+)$ staphylococci were ingested in the presence of fibrin than reported by the above authors.

The diminished ingestion of $(\mathrm{C}+)$ staphylococci in streptokinase-treated blood was an unexpected finding. This was probably not due to a direct effect of streptokinase on leucocytes because a comparable amount of the enzyme did not affect the ingestion of either $(\mathrm{C}-)$ or $(\mathrm{C}+)$ staphylococci in the absence of fibrinogen. It might have been due to incomplete removal of fibrinogen by streptokinase, although sufficient enzyme was added to lyse completely the clot which formed spontaneously after drawing the blood; moreover, there was no gross or microscopic evidence of fibrin in the streptokinase-treated blood after incubation for one hour with $(\mathrm{C}+$ ) staphylococci. However, special fibrin stains were not used in these studies.

Ingestion of $(C+)$ staphylococci compared with ingestion of $(C-)$ staphylococci. The mean ingestion of (C-) staphylococci was greater than that of $(\mathrm{C}+)$ staphylococci in heparinized blood. This difference was significant. In contrast phagocytosis of $(\mathrm{C}+)$ staphylococci was greater than that of $(\mathrm{C}-$ ) staphylococci both in blood defibrinated by glass beads and in defibrinated blood to which streptokinase had been added. There was no significant difference in the mean ingestion of the two species of staphylococci in the streptokinase-treated blood. It is possible that the latter finding was due to incomplete removal of fibrinogen which resulted in decreased ingestion of $(C+)$ strains as discussed above.

\section{Petri dish technique}

The Petri dish technique was devised for two reasons; first, to attempt to record quantitatively the phagocytosis of $(\mathrm{C}+)$ staphylococci exposed

TABLE I

Ingestion of staphylococci by neutrophils in blood containing heparin or streptokinase, or in blood defibrinated with glass beads

(Roller tube techrique-17 subjects)

\begin{tabular}{|c|c|c|c|c|c|}
\hline Blood preparation & $\begin{array}{c}\text { Average } \\
\text { neutrophil } \\
\text { count per } \\
\text { cu. mm. }\end{array}$ & $\begin{array}{c}\text { Number } \\
\text { neutrophils } \\
\text { counted }\end{array}$ & $\begin{array}{c}\text { Micro- } \\
\text { organism* }\end{array}$ & $\begin{array}{c}\text { Mean } \\
\text { ingestion } \\
\text { per } \\
\text { neutrophil }\end{array}$ & $\begin{array}{l}\text { Standard } \\
\text { error }\end{array}$ \\
\hline Blood plus heparin & 3,770 & $\begin{array}{l}3,400 \\
800 \ddagger\end{array}$ & $\stackrel{\text { C+ }}{\text { C- }}$ & $\begin{array}{l}15.7 \\
20.4\end{array}$ & $\begin{array}{l} \pm 1.0 \\
\pm 1.8\end{array}$ \\
\hline Blood plus streptokinase & 3,500 & $\begin{array}{r}3,400 \\
850\end{array}$ & $\stackrel{\mathrm{C}}{\mathrm{C}}-$ & $\begin{array}{l}23.0 \\
23.7\end{array}$ & $\begin{array}{l} \pm 2.8 \\
\pm 2.6\end{array}$ \\
\hline Defibrinated blood $\dagger$ & 3,540 & $\begin{array}{r}3,400 \\
850\end{array}$ & $\stackrel{\mathrm{C}+}{\mathbf{C}}-$ & $\begin{array}{l}32.7 \\
22.0\end{array}$ & $\begin{array}{l} \pm 1.6 \\
\pm 1.7\end{array}$ \\
\hline $\begin{array}{l}\text { Defibrinated blood } \dagger \\
\text { plus streptokinase }\end{array}$ & 3,540 & $\begin{array}{r}3,400 \\
850\end{array}$ & $\stackrel{\mathrm{C}}{\mathrm{C}}-$ & $\begin{array}{l}33.5 \\
23.9\end{array}$ & $\begin{array}{l} \pm 1.6 \\
\pm 1.9\end{array}$ \\
\hline
\end{tabular}

* $\mathrm{C}+$ = coagulase positive strains I, II, III, and IV.

C - coagulase negative.

$\dagger$ Defibrinated with glass beads.

$\$ 16$ subjects. 
only to neutrophils in a fibrin clot. This was accomplished by adding thrombin to blood as soon as microorganisms and neutrophils were mixed. Hale and Smith (1) pointed out that the ingestion of $(\mathrm{C}+)$ staphylococci in plasma probably occurs before fibrin has been deposited as a result of coagulase activity. However, in warm stage preparations leucocytes may be seen to move in a fibrin clot, so it seemed important to attempt to measure phagocytosis when fibrin was present at the initial exposure of microorganisms to leucocytes. A second reason for using the Petri dish technique was to compare the ingestion of type II encapsulated pneumococci in the presence or absence of a fibrin clot. The effect of type specific antibody under the same conditions could then be studied.

The mixtures were not agitated constantly during incubation; but because the average ratio of bacteria to neutrophils was approximately $50: 1$, it is reasonable to assume that there was adequate contact between them.

Table II records data on the phagocytosis of staphylococci and pneumococci in three different blood preparations: blood plus heparin, blood plus streptokinase, and blood defibrinated with glass beads.

Ingestion of (C-) staphylococci. There was no significant difference in the ingestion of $(\mathrm{C}-$ ) staphylococci by neutrophils in any of the blood preparations, showing that in these experiments, thrombin, heparin, streptokinase, or defibrination with glass beads did not affect phagocytosis.

Ingestion of $(C+)$ staphylococci. The mean ingestion of $(C+)$ staphylococci by neutrophils was greatest in defibrinated blood, somewhat smaller in heparinized blood, and least in streptokinase-treated blood. These differences are statistically significant. There is no obvious explanation for the relatively low mean ingestion in streptokinase-treated blood unless it was the presence of an additional 1,200 units of streptokinase in this preparation. But, as reported above, under identical conditions no significant difference was found in the ingestion of $(\mathrm{C}-)$ staphylococci. The mean ingestion of $(\mathrm{C}+)$ staphylococci by neutrophils in heparinized blood was higher in Petri dishes than in roller tubes. This was probably due to the addition of streptokinase to the former at the end of one hour's incubation; fibrinolysis

TABLE II

Ingestion of microorganisms in blood containing heparin, or streptokinase, or in blood defibrinated with glass beads (Number neutrophils counted per microorganism-1,000, Petri dish technique, 20 subjects)

\begin{tabular}{|c|c|c|c|c|c|}
\hline Blood preparation* & $\begin{array}{l}\text { Average } \\
\text { neutrophil } \\
\text { count per } \\
\text { cu. mm. }\end{array}$ & Microorganism & $\begin{array}{l}\text { Clot formed } \\
\text { after } \\
\text { addition of } \\
\text { thrombin }\end{array}$ & $\begin{array}{c}\text { Mean } \\
\text { ingestion } \\
\text { per } \\
\text { neutrophil }\end{array}$ & $\begin{array}{l}\text { Standard } \\
\text { error }\end{array}$ \\
\hline Blood plus heparin & 4,200 & $\begin{array}{c}\text { Staphylococcus }(\mathrm{C}+) \dagger \\
\text { Staphylococcus }(\mathrm{C}-) \\
\text { Rough pneumococcus } \\
\text { Type II pneumococcus } \\
\text { Type II pneumococcus } \\
\text { plus antibody }\end{array}$ & $\begin{array}{l}+ \\
+ \\
+ \\
+\end{array}$ & $\begin{array}{r}25.3 \\
15.4 \\
21.7 \\
7.8 \\
11.2\end{array}$ & $\begin{array}{l} \pm 1.1 \\
\pm 0.9 \\
\pm 1.3 \\
\pm 0.4 \\
\pm 1.1\end{array}$ \\
\hline $\begin{array}{l}\text { Blood plus } \\
\text { streptokinase } \\
\text { (1,200 units) }\end{array}$ & 3,800 & $\begin{array}{c}\text { Staphylococcus }(\mathbf{C}+) \dagger \\
\text { Staphylococcus }(\mathbf{C}-) \\
\text { Rough pneumococcus } \\
\text { Type II pneumococcus } \\
\text { Type II pneumococcus } \\
\text { plus antibody }\end{array}$ & $\begin{array}{l}\overline{-} \\
\overline{-} \\
-\end{array}$ & $\begin{array}{r}19.5 \\
11.6 \\
21.8 \\
0.3 \\
12.0\end{array}$ & $\begin{array}{l} \pm 1.9 \\
\pm 1.9 \\
\pm 2.1 \\
\pm 0.2 \\
\pm 2.3\end{array}$ \\
\hline $\begin{array}{l}\text { Defibrinated } f \\
\text { blood }\end{array}$ & 4,100 & $\begin{array}{l}\text { Staphylococcus }(\mathrm{C}+) \dagger \\
\text { Staphylococcus }(\mathrm{C}-)^{\dagger} \\
\text { Rough pneumococcus } \\
\text { Type II pneumococcus } \\
\text { Type II pneumococcus } \\
\text { plus antibody }\end{array}$ & $\begin{array}{l}\bar{z} \\
\overline{-} \\
-\end{array}$ & $\begin{array}{r}33.6 \\
14.8 \\
28.3 \\
0.7 \\
13.0\end{array}$ & $\begin{array}{l} \pm 2.5 \\
\pm 1.3 \\
\pm 2.7 \\
\pm 0.2 \\
\pm 1.4\end{array}$ \\
\hline
\end{tabular}

* 1,250 units streptokinase added to all preparations 1 hour after addition of thrombin. Mixtures then incubated for a further 1-hour period.

Coagulase positive, strain I.

$\mp$ Defibrinated with glass beads. 
during the second hour of the experiment allowed further ingestion to occur as the preparation liquefied. Another possibility is that fibrinogen was removed following the addition of thrombin. If fibrinogen is closely related to phagocytosis, its elimination may have allowed increased phagocytosis. The attempt to measure phagocytosis of (C+) staphylococci in the presence of fibrin only, failed owing to our inability to inactivate neutrophils while fibrinolysis was occurring.

Ingestion of $(C+)$ staphylococci compared with that of $(C-)$ staphylococci. Significantly more $(\mathrm{C}+$ ) staphylococci were ingested than $(\mathrm{C}-$ ) staphylococci in all blood preparations. Because fibrin was not a constant factor in determining phagocytosis of staphylococci as measured in the Petri dish technique (owing to fibrinolysis during the second hour of the experiment), the observed differences are most likely the result of chemotaxis.

Ingestion of type II pneumococci. There was a marked increase in the ingestion of encapsulated type II pneumococci in the presence of fibrin strands (blood plus heparin), compared with ingestion of the microorganisms in streptokinasetreated blood or defibrinated blood. The addition of specific antibody to the heparinized blood mixtures resulted in a further increase in encapsulated pneumococcal ingestion. The latter increase was relatively small but under the experimental conditions statistically significant. The addition of specific antibody to the streptokinase-treated or defibrinated blood preparations also resulted in a greatly increased ingestion of encapsulated pneumococci, compared with their ingestion in the absence of antibody. Here too, mean ingestion was somewhat greater than that which occurred in the presence of fibrin only.

Ingestion of rough pneumococci. Statistical analysis of the data on the ingestion of rough pneumococci (variant of the encapsulated type II pneumococcus) in the three blood preparations revealed no clear-cut difference. However, the rough strain was ingested in much greater numbers than the encapsulated strain to which type specific antibody had been added.

Ingestion of $(C+)$ staphylococci compared with that of encapsulated pneumococci. The mean ingestion of $(\mathrm{C}+)$ staphylococci was much greater than that of encapsulated pneumococci, especially in the absence of fibrin. These findings show a basic difference in the ability of neutrophils to ingest $(\mathrm{C}+)$ staphylococci and encapsulated pneumococci. Whereas, phagocytosis of staphylococcus is relatively easy, the large capsule about the pneumococcus effectively protects against neutrophil ingestion in a fluid medium.

\section{DISCUSSION}

The observations reported in the present paper confirm findings of others on the apparent influence of fibrin on the phagocytosis of staphylococci and of pneumococci $(1,2,5)$. It appears to play a passive role and influences ingestion differently depending on the microorganism studied. Fibrin probably impedes neutrophil mobility and so limits optimal contact between leucocytes and microorganisms. But actual ingestion of $(\mathrm{C}+)$ staphylococci may be hindered by the interposition of a fibrin coat between the staphylococcus and the neutrophil. Encapsulated pneumococci are more readily ingested in a fibrin clot which has been produced by thrombin activity. Here the fibrin strands serve as a barrier against which the microorganisms can be pushed to facilitate ingestion. There is another possible explanation for the differing effect of fibrin on the ingestion of $(C+)$ staphylococci and encapsulated pneumococci. Data presented in this study demonstrated that a significant reduction in phagocytosis of $(\mathrm{C}+)$ staphylococci occurred in the presence of fibrin, but failed to show that their ingestion was impossible under these conditions. Neutrophils may be seen to move among fibrin strands in warm stage preparations so it is possible that some ingestion of (C+) staphylococci occurs in fibrin clots. If this is true, the apparent paradox in the role of fibrin on the ingestion of staphylococci and pneumococci could be explained by the fact that both microorganisms are ingested to some extent in the presence of fibrin; but a limiting effect can only be shown with the staphylococcus. Hale and Smith (1) showed that as the exposure time of microorganism to leucocytes in plasma was increased, (C+) staphylococcal ingestion was decreased. They interpret this as evidence that ingestion of (C+) microorganisms occurs before fibrin forms due to coagulase activity, but this experiment is not inconsistent with the above hypothesis. 
The formation of fibrin may not be the only factor which influences the ingestion of $(C+)$ staphylococci by neutrophils in plasma. Several investigators (14-16) have reported that $(C+)$ staphylococci clump rapidly when suspended in plasma. This is apparently related to the presence of fibrinogen and usually does not occur in serum; clumping also occurs in fibrinogen solutions (16). If such clumped $(C+)$ staphylococci resisted neutrophil ingestion, consideration of this fact would be required in the interpretation of the results of the present experiments. A suspension of the $(C+)$ strains used in the present study did clump rapidly when tested by the slide-test against two samples of plasma, but they also clumped in sera from the same subjects. The presence of clumping was not looked for in this study so that its effect on the observed phagocytosis cannot be assessed.

The significance of coagulase production in human staphylococcal infections cannot be assessed by the present experiments. The finding of excellent phagocytosis in the presence of fibrin supports the opinion of other investigators (2) that coagulase may not be of prime importance in staphylococcal pathogenicity.

Data presented on the phagocytosis of encapsulated pneumococci in fibrin clots are of great interest in that they permit a quantitative definition of the phenomenon of surface phagocytosis. Exposure of encapsulated type II pneumococci to neutrophils in a fibrin clot resulted in a marked increase in mean ingestion, although antibody was absent. In the presence of type specific antibody mean ingestion was further increased by about 50 per cent. It is clear, however, from these data that "surface phagocytosis" of encapsulated type II pneumococci is nearly as efficient as opsoninpotentiated phagocytosis. This supports the opinion of Wood, Smith, and Watson (4) that "surface phagocytosis" may be an important feature in combatting natural pneumococcal infection prior to the formation of specific antibody.

The influence of streptokinase on the phagocytosis of $(\mathrm{C}+)$ staphylococci is not entirely clear. The data show that it does not affect the ingestion of coagulase negative staphylococci, rough pneumococci, or opsonized type II encapsulated pneumococci; but when added to plasma, streptokinase appears to hinder the ingestion of $(\mathrm{C}+)$ staphy- lococci, even though such blood will not clot. The addition of an equal amount of streptokinase to blood defibrinated with glass beads does not influence phagocytosis of the same organisms. All these data suggest that streptokinase does not affect neutrophil activity per se. A possible explanation is that the quantity of streptokinase used was insufficient to remove all the fibrinogen from the plasma and so coagulase still promoted the coating of individual staphylococci by fibrin. However, we found no gross or microscopic evidence of fibrin formation following coagulase activity in the preparations.

The observations reported in this paper suggest that the removal of fibrin by streptokinase may be of some value in the local therapy of coagulase positive staphylococcal infection, because mean ingestion was improved over that occurring in heparinized blood. But in pneumococcal infection, it seems likely that streptokinase therapy would impede phagocytosis of encapsulated pneumococci if used to remove fibrin before the appearance of specific antibody.

\section{SUMMARY}

1. The production of coagulase by staphylococci diminishes the ingestion of these organisms by neutrophil polymorphonuclear leucocytes.

2. The phenomenon of "surface phagocytosis" of encapsulated pneumococci has been confirmed and defined quantitatively. Mean ingestion by this mechanism was about 65 per cent of that occurring in the presence of specific antibody.

3. Data are presented showing that the removal of fibrin by streptokinase will prevent significant ingestion of encapsulated pneumococci if specific antibody is absent.

\section{REFERENCES}

1. Hale, J. H., and Smith, W., The influence of coagulase on the phagocytosis of staphylococci. Brit. J. Exper. Path., 1945, 26, 209.

2. Rogers, D. E., and Tompsett, R., The survival of staphylococci within human leukocytes. J. Exper. Med., 1952, 95, 209.

3. Wood, W. B., Jr. Smith, M. R., and Watson, B., Surface phagocytosis-its relation to the mechanism of recovery in pneumococcal pneumonia. Science, 1946, 104, 28.

4. Wood, W. B., Jr., Smith, M. R., and Watson, B., Studies on the mechanism of recovery in pneumococcal pneumonia. IV. The mechanism of phago- 
cytosis in the absence of antibody. J. Exper. Med., 1946, 84, 387.

5. Smith, M. R., and Wood, W. B., Jr., Relation of surface phagocytosis to the fibrinous character of acute bacterial exudates. Science, 1949, 110, 187.

6. Tillett, W. S., Sherry, S., Christensen, L. R., Johnson, A. J., and Hazlehurst, G., Streptococcal enzymatic débridement. Ann. Surg., 1950, 131, 12.

7. Tillett, W. S., Sherry, S., and Read, C. T., The use of streptokinase-streptodornase in the treatment of postpneumonic empyema. J. Thoracic Surg., 1951, 21, 275.

8. Jung, R. W., The importance of leucocyte counts in phagocytic tests. J. Lab. \& Clin. Med., 1936, 21, 760.

9. Hanks, J. H., Quantitative aspects of phagocytosis as influenced by the numbers of bacteria and leucocytes. J. Immunol., 1940, 38, 159.

10. Boerner, F., and Mudd, S., Determination of phagocytic power of whole blood or plasma-leukocyte mixtures for clinical or experimental purposes.
Description of improved method, with representative findings. Am. J. Med. Sc., 1935, 189, 22.

11. Rigdon, R. H., and Schrantz, F. S., Effect of heparin on phagocytosis by the cells of the reticulo-endothelial system. Ann. Surg., 1942, 116, 122.

12. Rigdon, R. H., Effect of heparin on phagocytosis; observations on P. lophurae in the chick. J. Lab. \& Clin. Med., 1944, 29, 840.

13. Johnson, A. J., Cytological studies in association with local injection of streptokinase-streptodornase into patients. J. Clin. Invest., 1950, 29, 1376.

14. Much, $H$., Uber eine Vorstufe des Fibrinfermentes in Kulturen von Staphylokokkus aureus. Biochem. Ztschr., 1908, 14, 143.

15. Birch-Hirschfeld, L., Uber die Agglutination von Staphylokokken durch Bestandteile des Säugetierblutplasmas. Klin. Wchnschr., 1934, 13, 331.

16. Cadness-Graves, B., Williams, R., Harper, G. J., and Miles, A. A., Slide-test for coagulase-positive staphylococci. Lancet, 1943, 1, 736. 